DOI: 10.12957/demetra.2017.27519

\title{
Qualidade microbiológica da comida de rua de Belo Horizonte, Minas Gerais
}

\author{
Microbiological quality of street foods in Belo Horizonte, Minas Gerais
}

\author{
Marlene Azevedo Magalhães Monteiro' \\ Daniella Bruno Dutra \\ Flávia Alcântara Torres' \\ Roseane Batitucci Passos de Oliveira ${ }^{2}$ \\ Rita de Cássia Ribeiro² \\ Maria Aparecida Vieira Teixeira Garcia ${ }^{2}$ \\ 1 Universidade Federal de Minas Gerais, Escola \\ de Enfermagem, Departamento de Nutrição. Belo \\ Horizonte-MG, Brasil. \\ ${ }^{2}$ Universidade Federal de Minas Gerais, \\ Faculdade de Farmácia, Departamento de \\ Alimentos. Belo Horizonte-MG, Brasil. \\ Fontes de Financiamento: Fundação de Amparo \\ à Pesquisa de Minas Gerais - FAPEMIG (Edital \\ FAPEMIG No 07/2011 - Apoio a Projetos de \\ Extensão em Interface com a Pesquisa). \\ Correspondência / Correspondence \\ Marlene Azevedo Magalhães Monteiro \\ E-mail:marleneaz@enf.ufmg.br
}

\section{Resumo}

O objetivo deste estudo foi analisar a qualidade microbiológica dos alimentos comercializados pelos ambulantes de Belo Horizonte, MG. A amostra foi definida estatisticamente e composta por 51 ambulantes de alimentos: 48 concordaram em responder ao questionário socioeconômico e a lista de verificação; 50, a aferição da temperatura do alimento; e 5 , a análise microbiológica (alimento, utensílio e mão do ambulante). A média de idade foi de 41 anos ( $\mathrm{DP} \pm 15), 21 \%$ das sobras eram reaproveitadas, $43,8 \%$ dos ambulantes não mantinham os cabelos protegidos por touca ou rede, $87,5 \%$ manuseavam dinheiro antes de manipular alimentos. Apenas $18,7 \%$ dos alimentos quentes apresentaram temperaturas adequadas conforme o padrão adotado. Foram encontradas inadequações para Aeróbios Mesófilos Viáveis (100\%), Coliformes a 35ㅇ C (60\%), Staphylococcus aureus (60\%), Bacillus cereus (20\%) e Salmonella spp. (60\%). Todas as amostras de utensílios foram consideradas com má higienização, e coliformes a $35^{\circ} \mathrm{C}$ estiveram presentes em todas as mãos dos ambulantes analisadas. As condições de infraestrutura, higienização dos equipamentos e utensílios e higiene pessoal dos entrevistados estavam deficientes. Faz-se necessário intervir e capacitar os ambulantes para que a comercialização dos alimentos ocorra de forma segura para o consumidor. Além disso, é preciso elaborar uma legislação sanitária específica para este tipo de comércio.

Palavras-chave: Comida de Rua. Segurança dos Alimentos. Vigilância Sanitária. 


\section{Abstract}

The objective of this study is to analyze the microbiological quality of food sold by street vendors of Belo Horizonte, MG. The sample defined statistically consisted of 51 itinerant food vendors, 48 of who agreed to answer the socioeconomic questionnaire and the verification list, 50 the temperature verification of the foods and five participated in the microbiological analysis (food, utensil and hand of street vendors). The mean age found was 41 years (SD \pm 15), $21 \%$ of the leftovers were reused, $43.8 \%$ of the food vendors did not protect their hair in a cap or net, $87.5 \%$ handled money before handling food. Only $18.7 \%$ of the hot foods showed appropriate temperature according to the adopted standard. In the food samples, inappropriate levels of Viable Aerobic Mesophilic (100\%) microorganisms, coliforms at $35^{\circ} \mathrm{C}(60 \%)$, Staphylococcus aureus (60\%), Bacillus cereus (20\%) and Salmonella spp. (60\%) were found. All utensil samples were considered badly washed and coliforms at $35^{\circ} \mathrm{C}$ were present on all every hand of street food analyzed. Interventions are needed that itinerant food vendors need to be trained with a view to the safe production of these foods for the consumers. Also, prepare a specific health legislation for this trade.

Keywords: Street Food. Safety of Street. Health Surveillance.

\section{Introdução}

O trabalho informal vem crescendo a cada ano no mundo inteiro, especialmente em países em desenvolvimento, onde é favorecido por altos índices de desemprego, baixo poder aquisitivo da população e acesso limitado à educação e ao mercado formal., ${ }^{1,2}$ Nesse contexto, percebe-se o aumento no número de vendedores ambulantes nas cidades, comercializando ou preparando alimentos. ${ }^{1}$ Esta expansão não se deve somente à possibilidade de emprego para a população, mas também ao acesso a uma diversidade de alimentos de menor custo para famílias de baixa renda. ${ }^{3}$

Segundo dados da Pesquisa de Orçamentos Familiares (POF 2008-2009), ${ }^{4}$ estima-se que, nos grandes centros brasileiros, cerca de $30 \%$ das refeições são realizadas fora do domicílio e que a população destina, em média, a parcela de 33,1\% das despesas alimentares com este tipo de refeição. Estudos desenvolvidos em vários países revelam que a contaminação microbiana destes produtos é irrefutável, partindo do pressuposto de que as condições de higiene e manipulação destes alimentos podem estar insatisfatórias, visto a escassez de recursos nos locais de comércio. ${ }^{3,5-12}$

Vendedores de comida de rua comercializam seus produtos em locais com trânsito numeroso de pessoas e veículos e que normalmente não cumprem todos os requisitos de segurança alimentar. ${ }^{7}$ As condições ambientais, bem como a falta de equipamentos de refrigeração, fontes de água potável, 
higiene pessoal dos manipuladores e instalações sanitárias públicas, além de aumentar as chances de contaminação, favorecem o crescimento bacteriano. ${ }^{6}$ Além disso, os alimentos preparados e armazenados de forma inadequada podem ser carreadores de microrganismos, como Salmonella spp, Vibrio cholerae, Staphylococcus aureus, e coliformes, ${ }^{2,13}$ e essa contaminação pode ser reduzida com a aplicação das Boas Práticas de Fabricação/Manipulação em toda a cadeia produtiva. ${ }^{14}$

Diante do exposto, o objetivo deste estudo foi avaliar a qualidade microbiológica de alimentos comercializados pelos ambulantes em Belo Horizonte, MG.

\section{Métodos}

Este estudo foi realizado na região Centro-Sul de Belo Horizonte, Minas Gerais, no ano de 2013, no período de fevereiro a setembro, constituindo-se de duas etapas. Para esta investigação, delimitou-se os espaços públicos com grande fluxo de pessoas, com maior concentração de ambulantes de alimentos.

A avaliação foi realizada por meio de questionário socioeconômico e uma lista de verificação, composta por questões objetivas e questões observadas pelo entrevistador. A lista de verificação, elaborada de acordo com a metodologia de Amson, ${ }^{15}$ compreendeu temas organizados em quatro blocos: condições ambientais (características do local, local de instalação, controle de pragas, resíduos, iluminação e instalação elétrica e abastecimento de água potável); manipulação dos alimentos (identificação das matérias-primas, ingredientes e produtos industrializados, rotatividade e armazenamento); higiene pessoal do ambulante (vestuário, hábitos higiênicos, estado de saúde e programa de capacitação dos manipuladores de alimentos e supervisão); e utensílios, equipamentos e carrinhos (utensílios de manipulação de alimentos, equipamentos, higienização de utensílios e equipamentos, carrinhos, local onde os carrinhos são guardados e higienização dos carrinhos).

Para o cálculo amostral dos bairros da região Centro-Sul, utilizou-se o programa estatístico Sample Size Calculate ${ }^{16}$ empregando nível de confiança de 95\% e uma margem de erro de $20 \%$. Dessa forma, a amostra foi composta por 11 bairros aleatórios da região Centro-Sul. Nestes bairros, 51 comerciantes ambulantes de alimentos foram convidados a participar deste estudo, porém, apenas 48 concordaram em responder ao questionário socioeconômico e à lista de verificação.

Os ambulantes que responderam ao questionário socioeconômico e à lista de verificação foram predominantemente do sexo feminino (52,1\%, n=25), com idade média de 41 anos (mínimo: 17 anos; máximo: 76 anos; $\mathrm{DP} \pm 15$ anos), nível de escolaridade (35,4\%, n=17) de primeiro grau incompleto, e o horário de trabalho mais frequente foi o que contempla os dois turnos, diurno e noturno.

Após a entrevista, foi aferida a temperatura dos alimentos prontos comercializados pelos entrevistados (50 ambulantes participaram desta etapa). Foi utilizado termômetro digital de 
infravermelho, com intervalo de temperatura de $50^{\circ} \mathrm{C}$ negativos a $350^{\circ} \mathrm{C}$ positivos. Para verificar a adequação das temperaturas aferidas, foi adotado como padrão o preconizado pela legislação vigente, que diz que alimentos quentes devem permanecer à temperatura igual ou superior a $60^{0}$ C por no máximo seis horas, enquanto alimentos resfriados não devem ultrapassar a temperatura de $10^{\circ} \mathrm{C}$ durante quatro horas de exposição.

$\mathrm{Na}$ segunda etapa, foram selecionados aleatoriamente cinco ambulantes participantes da primeira etapa, para coleta e análise microbiológica de uma amostra de alimento comercializado, conforme descrito na Tabela 1, mão do manipulador e de um utensílio (pegador em aço inoxidável). O critério utilizado para seleção dos ambulantes foi a comercialização de algum dos alimentos objetos de estudo. No momento da coleta da amostra do alimento, foi aferida também sua temperatura, para avaliar a existência ou não de inconformidade.

Tabela 1. Avaliação microbiológica de alimentos, utensílios e mão de ambulantes da região Centro-Sul de Belo Horizonte/MG, 2013.

\begin{tabular}{|c|c|c|c|c|c|c|c|}
\hline & \multirow[b]{2}{*}{ AMOSTRA } & \multicolumn{6}{|c|}{ PARÂMETRO } \\
\hline & & $\mathrm{AMV}^{1}$ & S. aureus & B. cereus & $\begin{array}{c}\text { Colif." } \\
45^{\circ} \mathrm{C}\end{array}$ & $\begin{array}{l}\text { Colif. } \\
35^{\circ} \mathrm{C} .\end{array}$ & Salmonella spp \\
\hline \multirow{3}{*}{1} & Macarrão na chapa & $5,14^{2}$ & $3,67^{2}$ & $2,52^{2}$ & $<1,00^{2}$ & $4,30^{2}$ & Ausência ${ }^{3}$ \\
\hline & Utensílio & $4,03^{4}$ & $* *$ & $* *$ & $<1,00^{4}$ & $2,02^{4}$ & \\
\hline & Mão & $* *$ & $3,87^{5}$ & $* *$ & $<1,00^{5}$ & $2,61^{5}$ & \\
\hline \multirow{3}{*}{2} & Hambúrguer & 4,94 & 3,97 & 2,75 & $<1,00$ & 1,78 & Ausência \\
\hline & Utensílio & 2,92 & $* *$ & $* *$ & $<1,00$ & 1,00 & \\
\hline & Mão & $* *$ & 2,04 & $* *$ & $<1,00$ & $<1,00$ & \\
\hline \multirow{3}{*}{3} & Cachorro-quente & 4,95 & 4,46 & 4,20 & $<1,00$ & $<1,00$ & Presença \\
\hline & Utensílio & 2,68 & $* *$ & $* *$ & $<1,00$ & 3,14 & \\
\hline & Mão & $* *$ & 1,30 & $* *$ & $<1,00$ & $<1,00$ & \\
\hline \multirow{3}{*}{4} & Hambúrguer & 5,18 & $>4,48$ & $<1,00$ & $<1,00$ & 2,60 & Presença \\
\hline & Utensílio & 3,43 & $* *$ & $* *$ & $<1,00$ & 2,00 & \\
\hline & Mão & $* *$ & $<1,00$ & $* *$ & $<1,00$ & $<1,00$ & \\
\hline \multirow{3}{*}{5} & Hambúrguer & 4,90 & 4,66 & 2,10 & 0,70 & 4,15 & Presença \\
\hline & Utensílio & 3,25 & $* *$ & $* *$ & $<1,00$ & 1,00 & \\
\hline & Mão & $* *$ & 3,00 & $* *$ & $<1,00$ & 1,30 & \\
\hline
\end{tabular}

"Coliformes; **NR: não realizado.

${ }^{1}$ Aeróbios mesófilos viáveis; ${ }^{2} \log$ UFC/g; ${ }^{3}$ ausência/presença em 25 g; ${ }^{4} \log$ UFC/UT; ${ }^{5} \log$ UFC/MÃO. 
Todas as amostras de alimentos coletadas foram transferidas para sacos plásticos estéreis, sendo identificados e lacrados e transportados em caixas de polietileno expandido contendo gelo para o Laboratório de Microbiologia de Alimentos, localizado no Departamento de Alimentos/campus Pampulha, da Faculdade de Farmácia da Universidade Federal de Minas Gerais, Belo HorizonteMG. O tempo decorrido entre a coleta do material e a análise microbiológica não ultrapassou 24 horas. As amostragens de mão e utensílio foram realizadas pelo método de $s w a b .{ }^{17}$

Para as análises dos alimentos, utilizaram-se os parâmetros Aeróbios Mesófilos Viáves (AMV), Coliformes a $35^{\circ} \mathrm{C}$ e a $45^{\circ} \mathrm{C}$, Salmonella ssp., Staphylococcus aureus e Bacillus cereus; para mãos, a contagem de Coliformes a $35^{\circ} \mathrm{C}$ e a $45^{\circ} \mathrm{C}$ e Staphylococcus aureus; e para os utensílios, os parâmetros AMV e Coliformes a $35^{\circ} \mathrm{C}$ e a $45^{\circ} \mathrm{C} . .^{18}$

Para verificar a adequação das amostras, foi adotado como parâmetro a tolerância para amostra indicativa, de acordo com a legislação brasileira. ${ }^{19,20}$ Para as contagens em alimentos de Coliformes a $35^{\circ} \mathrm{C}$, os valores limites de 2,0 log UFC/g, e para Coliformes a 45을 C, Staphylococcus aureus, Bacillus cereus e Salmonella spp., ${ }^{17,21}$ os valores máximos de 2,0 log UFC/g, 3,0 log UFC/g, 3,0 log UFC/g, respectivamente, salvo para Salmonella spp, sendo sua ausência em $25 \mathrm{~g}$ do alimento o desejável. ${ }^{19,20}$

Na determinação dos resultados da aplicação da lista de verificação, foram utilizados valores numéricos para os itens investigados, segundo metodologia de Valente \& Passos. ${ }^{22}$ A análise descritiva incluiu o cálculo das distribuições de frequências, médias e percentuais com auxílio do software Statistical Package for the Social Sciences (SPSS) versão 19.0.

Este estudo foi aprovado pelo Comitê de Ética em Pesquisa da Universidade Federal de Minas Gerais sob o parecer nํㅡㄹ 0225.0.203.000-10.

\section{Resultados}

Avaliação das condições ambientais

A respeito das condições ambientais, foi observado que $87,5 \%(n=42)$ dos locais de comercialização dos alimentos encontravam-se próximos a bueiros e 93,8\% (n=45) estavam em áreas com grande movimento de veículos, sendo, em sua maioria, com sujeira aparente. O piso não estava em adequado estado de conservação em 93,8\% ( $n=45)$ dos locais, e em 91,7\% ( $n=44)$ havia objetos em desuso ou estranhos ao ambiente e/ou com acúmulo de lixo e/ou água estagnada.

Foram considerados recipientes adequados para a coleta de resíduos os que apresentaram fácil higienização e transporte, tampados com acionamento não manual, e uso de sacos de lixo apropriados. Entre os participantes, apenas 19,6\% (n=9) dos comerciantes estavam apropriados nos quesitos citados, sendo que $34 \%$ (n=16) alegaram a retirada frequente dos resíduos. A presença de pragas como moscas foi observada em 58,3\% (n=28) dos ambulantes. 
A origem da água utilizada por $50 \%(\mathrm{n}=22)$ dos ambulantes da amostra provém de estabelecimentos comerciais, porcentual seguido peloda própria casa $(36,4 \%, \mathrm{n}=16)$ e de outros locais $(13,6 \%, \mathrm{n}=6)$, uma vez que $100 \%$ desta água estava armazenada em galóes.

\section{Avaliação da manipulação dos alimentos}

Os produtos mais comercializados pelos ambulantes foram pipoca e praliné $(33,8 \%, \mathrm{n}=18)$, seguidos por cachorro-quente $(20,3 \%, \mathrm{n}=9)$ e sanduíches $(13,5 \%, \mathrm{n}=6)$.

Com relação às práticas de manipulação dos alimentos, 20,8\% $(\mathrm{n}=10)$ das sobras eram reaproveitadas; 2,20\% ( $n=1)$ utilizavam maionese caseira e 14,60\% $(n=7)$, molhos e temperos em bisnagas. As embalagens usadas para comercializar os alimentos eram descartáveis (100\%; $\mathrm{n}=48)$. Porém, somente $52,10 \%(\mathrm{n}=25)$ dos ambulantes as armazenavam em local adequado.

O armazenamento dos alimentos, por sua vez, não era realizado de maneira correta (em local limpo organizado e em bom estado de conservação) em 58,30\% (n=28) dos casos observados. Além disso, em $75 \%(\mathrm{n}=36)$ dos locais, os alimentos não estavam guardados em recipientes apropriados (com identificação, acondicionados separadamente de outros produtos) e em temperatura adequada.

Cerca de 8,30\% $(\mathrm{n}=4)$ dos ambulantes entrevistados alegaram não possuir licença pela Prefeitura de Belo Horizonte ( $\mathrm{PBH}$ ) para o comércio ambulante de alimentos, e 72,90\% (n=35) nunca frequentaram curso relacionado à manipulação de alimentos.

\section{Avaliação da higiene pessoal do ambulante}

Notou-se que $93,60 \%(\mathrm{n}=44)$ dos ambulantes praticavam atos que poderiam contaminar os alimentos, entre eles, não manter os cabelos protegidos por touca ou rede $(43,8 \%$; $=21)$, manusear dinheiro antes de manipular alimentos $(87,5 \% ; n=42)$, além de conversar sobre o alimento no momento da manipulação, fumar, entre outros. Os estabelecimentos comerciais próximos foram os locais citados com mais frequência para realizar necessidades fisiológicas $(79,20 \%, \mathrm{n}=38)$.

No quesito estado de saúde, $85,10 \%$ ( $\mathrm{n}=40)$ dos ambulantes apresentavam-se com ausência de afecções cutâneas e feridas, e 31,30\% (n=15) relataram trabalhar quando doentes (gripe, infecções de garganta ou diarreia).

\section{Avaliação de utensílios, equipamentos e carrinhos}

Em 23,40\% ( $\mathrm{n}=11)$ dos carrinhos de armazenamento e transporte dos alimentos, os produtos de higienização estavam disponíveis, identificados e armazenados em local adequado. Sobre as 
condições higiênicas do local onde os carrinhos eram guardados, $40 \%$ ( $n=18)$ dos entrevistados alegaram ser uma área limpa, livre de objetos em desuso, focos de poeira, acúmulo de lixo e água estagnada. O local mais citado para guardar o carrinho foi um estacionamento coberto $(54,20 \%, \mathrm{n}=26)$.

\section{Temperatura dos alimentos}

Os alimentos/preparações quentes comercializados pelos ambulantes apresentaram temperaturas entre $24,10^{\circ} \mathrm{C}$ e $87,0^{\circ} \mathrm{C}$, sendo em $18,70 \%(\mathrm{n}=9)$ apropriadas conforme o padrão adotado. E os alimentos/preparações frios, compostos por duas amostras de água de coco, obtiveram temperaturas adequadas, abaixo de $10^{\circ} \mathrm{C}$.

\section{Análise microbiológica}

Os resultados da análise microbiológica das amostras de alimentos coletadas, utensílios e mãos dos ambulantes na região Centro-Sul de Belo Horizonte, MG estão na Tabela 1.

\section{Discussão}

No presente estudo, foram encontradas inadequações importantes em todos os quatro blocos (condições ambientais, manipulação dos alimentos, higiene pessoal do ambulante e utensílios, equipamentos e carrinhos), avaliados por meio da lista de verificação. Constatou-se a mesma inadequação na avaliação da temperatura e na análise microbiológica do alimento, mãos e utensílios utilizados pelos ambulantes.

Entre as condições ambientais, observou-se inadequação tanto na estrutura física do carrinho de armazenamento e transporte do alimento, como nos pontos de comercialização. Mesmo em alguns casos em que a estrutura física encontrava-se em bom estado, nenhum dos pontos de venda atendeu às determinações mínimas da legislação vigente. ${ }^{21}$

Visto que o comércio ambulante de alimentos é uma atividade legalizada, faz-se necessário a criação de uma legislação apropriada para as especificidades do ofício, integrando as boas práticas de manipulação com os padrões de condições físicas e estruturais existentes para o exercício desta atividade.

Outro problema observado foi o acúmulo de lixo em recipientes destampados, com retirada infrequente, proximidade da rede de esgoto e água estagnada. Em estudo com 158 pontos de venda de comida de rua em Taubaté-SP, Franco \& Ueno ${ }^{9}$ encontraram lixeira com pedal em 18,40\% dos 
pontos estudados, valor próximo ao achado neste estudo (19,60\%), enquanto Mallon \& Bortolozo ${ }^{10}$ não encontraram este tipo de lixeira, preconizado pela legislação vigente. ${ }^{21}$

Estes fatores propiciam a instalação e reprodução de pragas urbanas e vetores transmissores de doenças, como as enteroparasitoses, e a disseminação de microrganismos patogênicos, oferecendo riscos à saúde do consumidor por contaminação do alimento produzido..$^{21,23-25}$

Em outro estudo com cachorros-quentes comercializados nas ruas de Cerqueira César-SP, foi observada a presença de pombos em $100 \%$ dos locais, e insetos em $52 \%$ dos pontos de venda decorrente de cestos de lixo destampados. ${ }^{8}$ Entretanto, diferentemente desses autores, esta questão não foi respondida de acordo com o observado pelo entrevistador, e sim como relatado pelos entrevistados.

De acordo com os dados obtidos, a totalidade dos ambulantes utiliza galóes para o armazenamento de água. Esse resultado corrobora outro estudo que observou que aqueles comerciantes que trabalhavam em praças e avenidas usavam este mesmo equipamento. ${ }^{9}$ Segundo Siqueira et al., ${ }^{26} \mathrm{o}$ armazenamento em recipientes inadequados é uma das etapas em que a água pode sofrer contaminação.

Além das condições ambientais, a higiene dos manipuladores, o armazenamento de alimentos, a higiene do ambiente de trabalho e as etapas de pré-preparo e preparo dos alimentos são itens imprescindíveis para a produção de alimentos/refeições de boa qualidade. ${ }^{27}$

No presente estudo, observou-se que os entrevistados não atendiam aos quesitos de uniforme, unhas e mãos, adornos e proteção dos cabelos como o recomendado, assim como a prática de atos que poderiam evitar a contaminação dos alimentos. Rodrigues et al..$^{28}$ verificaram em seu trabalho que $55 \%$ dos vendedores ambulantes usavam adornos e $75 \%$ apresentavam unhas limpas e aparadas; resultados otimistas em relação aos encontrados neste estudo.

Outra atitude anti-higiênica verificada no momento da entrevista foi a prática de conversar sobre o alimento, uma fonte de contaminação para o mesmo (saliva). Esta observação também foi descrita por Lundgren et al. ${ }^{29} \mathrm{em}$ seu trabalho avaliando o perfil da qualidade higiênico-sanitária da carne bovina comercializada em feiras livres e mercados públicos de João Pessoa-PB. O ato concomitante de manipular dinheiro e alimento sem que haja higienização das mãos entre essas ações também foi frequentemente observado e se assemelha com o descrito em estudo de Rodrigues et al., ${ }^{11}$ no qual 87,50\% dos ambulantes mantinham este tipo de conduta errônea.

Outro dado preocupante foi a prevalência de entrevistados que afirmaram trabalhar quando doentes. A manipulação de alimentos é um dos fatores que requer maior controle a fim de garantir sua segurança. Estudos apontam que quando o manipulador de alimentos se mostra doente ou portador assintomático, é responsável por até $26 \%$ das Doenças Transmitidas pelos Alimentos (DTAs). ${ }^{30}$ Isso ressalta a importância da capacitação dos manipuladores quanto às Boas Práticas 
de Fabricação (BPF), já que a falta destas foi observada em mais de $70 \%$ dos entrevistados. Assim, sugere-se que se façam capacitações no local de trabalho dos ambulantes, uma vez que o expediente destes comerciantes inviabiliza a participação em cursos externos.

Os mesmos resultados inadequados foram encontrados por Rodrigues et al. ${ }^{11}$ no que se refere à higienização dos utensílios e equipamentos. As falhas nos procedimentos de higienização de equipamentos e utensílios permitem que os resíduos aderidos aos equipamentos e superfícies se transformem em potencial fonte de contaminação cruzada, sendo também responsáveis por surtos de doenças de origem alimentar. ${ }^{10,30}$

A avaliação da temperatura também revelou dados em inconformidade com a Portaria CVS 05/2013 ${ }^{21}$ e a Resolução RDC 216/2004, ${ }^{31}$ uma vez que a adequação foi em apenas $22 \%$ das amostras, valor superior, no entanto, ao encontrado em dois estudos conduzidos em Taubaté-SP e Paraíso-TO. ${ }^{11,32}$ É sabido que temperaturas fora do preconizado favorecem o crescimento de microrganismos patogênicos, causando danos à saúde do consumidor.

A análise microbiológica dos alimentos, utensílios e mão do ambulante também demonstrou resultados de inconformidade com a legislação vigente.

A presença de coliformes foi percebida em $60 \%$ das amostras analisadas dos alimentos e em $40 \%$ das dos utensílios e mãos dos ambulantes. Coliformes quando presentes podem indicar uma falha higiênica durante o processo de produção. Além disso, se não forem aplicadas práticas adequadas de armazenamento e comercialização, os patógenos intestinais associados a esse grupo podem atingir as doses infectivas, causando DTAs. ${ }^{15}$ Quando se observa a porcentagem de amostras positivas para presença de Salmonella spp (40\%) e a correlaciona com os dados obtidos na aplicação do questionário para a inadequação dos quesitos "ausência de higienização de mãos"; "manipula dinheiro e alimentos ao mesmo tempo" e "armazenamento inadequado de alimentos"; pode-se inferir que existe um grande risco de ocorrência de surtos de salmonelose no consumo desses alimentos.

Os alimentos mais suscetíveis à contaminação com Salmonella são os que contêm alto teor de umidade, proteína e carboidratos, como carne bovina, suínos, aves, ovos, leite/derivados, frutos do mar e sobremesas recheadas. ${ }^{2,10,15,28,32}$

A contagem de S. aureus neste estudo esteve superior aos padróes brasileiros em $80 \%$ das amostras (alimentos e mão do ambulante), representando a maior prevalência de contaminação entre os patógenos. Esse valor não é surpreendente, uma vez que o ser humano é um dos principais focos de contaminação deste microrganismo., ${ }^{2,10,13,15}$ Vale ressaltar que a higienização de mãos e a não utilização de toucas protetoras para os cabelos contabilizaram uma inadequação superior a $90 \%$ dos ambulantes. Esses dados sugerem que o contato entre as mãos e o alimento pode ter sido uma das causas de contaminação e confirmam a importância da higienização adequada das mãos como relevante etapa para prevenção da contaminação de alimentos. ${ }^{28,32}$ 
Das amostras analisadas para coliformes a $35^{\circ} \mathrm{C}, 60 \%$ tiveram valores superiores ao limite de 2,0 $\log \mathrm{UFC} / \mathrm{g}$. Este grupo é utilizado como indicador da potabilidade da água e das condições gerais higiênico-sanitárias do ambiente de processamento de alimentos. ${ }^{33}$

Rodrigues et al. ${ }^{28}$ observaram que $53 \%$ dos estabelecimentos estudados foram considerados insatisfatórios para amostras de cachorro-quente neste parâmetro. Enquanto Alves e Ueno, ${ }^{32}$ ao analisar coliformes a $35^{\circ} \mathrm{C}$ nos alimentos, identificaram 76,6\% de contaminação por esses microrganismos. Já para coliformes a $45^{\circ} \mathrm{C}$ ou coliformes de origem fecal ${ }^{19}$ não foram encontrados valores detectáveis em sua maioria, sendo que a presença desses microrganismos nos alimentos é tida como um indicador sanitário. ${ }^{34}$ Este resultado mostrou-se diferente de outros estudos, em que algumas amostras apresentavam contagens acima do preconizado pela legislação brasileira. ${ }^{35,36}$

Baseando-se na contagem de Staphylococcus aureus, duas amostras encontraram-se no limite de tolerância para amostras indicativas, enquanto as demais apresentaram um valor de UFC/g por alimento maior que este limite. $S$. aureus possui toxina termoestável e pode entrar em contato com os alimentos por meio de manipuladores infectados, especialmente em alimentos com alto grau de manipulação. É responsável por causar intoxicação pelo consumo de alimentos com toxinas pré-formadas, servindo assim como indicador de contaminação pós-processo ou das condições de sanitização das superfícies que entram em contato com alimentos. ${ }^{29,37}$

Outro tipo de intoxicação alimentar é aquela causada por Bacillus cereus, patógeno capaz de formar esporos, que tem sua multiplicação favorecida quando há abuso de tempo-temperatura. ${ }^{30}$ No entanto, apenas uma amostra se mostrou em inconformidade com o preconizado, o que é contraditório com os resultados de Bezerra et al., ${ }^{35}$ que, ao avaliar este microrganismo nas amostras, encontraram níveis aceitáveis pela legislação brasileira.

Salmonella spp., outro patógeno causador de Doenças Transmitidas por Alimentos (DTAs), diferentemente dos demais, tem sua ausência como preconização da Resolução RDC 12/2001, ${ }^{19}$ bem como em Forsythe, ${ }^{38} \mathrm{em}$ alimentos. Tal adequação não foi observada no presente estudo, que teve três de cinco amostras contaminadas com este microorganismo, sendo que nos estudos em geral essa presença ocorre em poucas amostras ou é inexistente. ${ }^{35,39}$ Os surtos ocasionados por Salmonella spp. ocorrem mais comumente pelo consumo de alimentos como frango, carne, ovos ou produtos lácteos, quando contaminados por material fecal ou pela conservação em temperaturas inadequadas. ${ }^{39,40}$ Estes fatores podem explicar o aparecimento desta bactéria nas amostras analisadas.

Não somente nas amostras dos produtos foi observada contaminação microbiológica. Com base nos padrões do Foods and Drusgs Administration - FDA e da American Public Health Association - APHA, ${ }^{17}$ todas as amostras de utensílios foram consideradas com má higienização.

Na análise das mãos dos ambulantes, encontrou-se contagem de coliformes a $35^{\circ} \mathrm{C}$ e $S$. aureus, corroborando outros estudos. ${ }^{35,41-43}$ Segundo Grando et al., ${ }^{44}$ o manuseio impróprio na preparação 
do alimento frequentemente é tido como a causa da contaminação deste por S. aureus. Além disso, o processo de higienização deficiente pode levar a essas contaminações. ${ }^{30}$ Nesse sentido, pode se inferir que a má higienização das mãos por parte dos ambulantes, dado constatado neste estudo, pode ser fonte de contaminação para o alimento.

Casos de DTAs ocorrem diariamente por todo o mundo. E como cerca de $30 \%$ das refeições são realizadas fora do domicílio nos grandes centros brasileiros, o preparo e comercialização de alimentos pelos ambulantes de forma inadequada constituem um problema de saúde pública. O despreparo dos manipuladores tem sido relacionado diretamente com a contaminação dos alimentos em virtude de doenças, maus hábitos de higiene e práticas inadequadas na produção. ${ }^{24,30}$

A ocorrência das DTAs no Brasil, entretanto, não é de notificação compulsória, o que impede a real avaliação do problema. ${ }^{8}$ A capacitação, nesse contexto, é de suma importância e pode ser encarada como uma forte aliada para assegurar a qualidade da alimentação comercializada. ${ }^{10,45}$

\section{Conclusão}

Os resultados obtidos neste estudo permitem concluir que as condições de infraestrutura, higienização dos equipamentos e utensílios, bem como higiene pessoal dos entrevistados, estavam deficientes, favorecendo vias de contaminação dos alimentos, refletida por meio da análise microbiológica dos alimentos comercializados e da aferição da temperatura. Para que a produção desses alimentos/preparações seja feita de forma segura para o consumidor, faz-se necessário intervir e capacitar os indivíduos que comercializam alimentos nas ruas, para que estes, através do conhecimento construído, possam atuar, minimizando os pontos críticos de contaminação dos produtos à venda.

\section{Colaboradores}

Monteiro MAM, Dutra DB, Torres FA e de Oliveira RBP participaram da análise e interpretação dos dados, redação do artigo, revisão crítica relevante do conteúdo intelectual e aprovação final da versão a ser publicada. Ribeiro RC e Garcia MAVT, da interpretação dos dados, redação do artigo, revisão crítica relevante do conteúdo intelectual e aprovação final da versão a ser publicada.

Conflito de interesses: Os autores declaram não haver conflito de interesses.

\section{Referências}

1. Soto FRM, Risseto MR, Lúcio D, Shimozako HJ, Camargo CC, Iwata MK, et al. Metodologia de avaliação das condições sanitárias de vendedores ambulantes de alimentos no Município de IbiúnaSP. Rev Bras Epidemiol. 2008; 11(2):297-303. 
2. Cardoso RCV, Santos SMC, Silva EO. Comida de rua e intervenção: estratégias e propostas para o mundo em desenvolvimento. Cienc Saude Colet. 2009; 14(4):1215-1224.

3. Rheinländer T, Olsen M, Bakang JA, Takyi H, Konradsen F, Samuelsen H, et al. Keeping up appearances: perceptions of street food safety in urban Kumasi, Ghana. J Urban Health 2008; 85(6):952-63.

4. Instituto Brasileiro de Geografia e Estatística. Pesquisa de Orçamento Familiar 2008-2009. [acesso em: 02 nov. 2012]. Disponível em: http://www.ibge.gov.br/home/estatistica/pesquisas/pesquisa_ resultados.php?id_pesquisa $=25$

5. Meshref AMS. Microbiological quality and safety of cooking butter in Beni-Suef governorate-Egypt. Afr Health Sci. 2010; 10(2):193-198.

6. El-Shenawy M, El-Shenawy M, Mañes J. et al. Listeria spp. in street vended ready to eat foods. Interdisc Persp Infec Diseas. 2011; 2011:1-6.

7. Muyanja C, Nayiga L, Brenda L, Nasinyama G. Practices, knowledge and risk factors of street food vendors in Uganda. Food Control. 2011; 22:1551-1558.

8. Lucca A, Torres EAFS. Condições higiênicas de cachorro-quente de rua. Rev Saude Publ. 2002; 36(3):350-352.

9. Franco CR, Ueno M. Comércio ambulante de alimentos: condições higiênico-sanitárias nos pontos de venda em Taubaté - SP. Cient Cienc Biol Saude 2010; 12(4):9-13.

10. Mallon C, Bortolozo EAF. Alimentos comercializados por ambulantes: uma questão de segurança alimentar. UEPG Cienc Biol Saude 2004; 10(3/4):65-76.

11. Rodrigues FM, Viroli SLM, Pavlk MCM, Sandi ALS. Avaliação das condições higiênico-sanitárias do comércio ambulante de alimentos na cidade de Paraíso do Tocantins. Rev ACTA Tecnol. 2010; 5(1):100-112.

12. Rane S. Street vended food in developing World: Hazard Analyses. Indian J Microb. 2011; 51(1):100-106.

13. Nkere CK, Ibe NI, Iroegbu CU. Bacteriological quality of foods and water sold by vendors and in restaurants in Nsukka, Enugu State, Nigeria: a comparative study of three microbiological methods. J Health Popul Nutr. 2011; 29(6):560-566.

14. Zandonadi RP, Botelho RBA, Sávio KEO, Akutsu RC, Araújo WMC. Atitudes de risco do consumidor em restaurantes de autosserviço. Rev Nutr. 2007; 20(1):19-26.

15. Amson GV. Comércio ambulante de alimentos em Curitiba: perfil de vendedores e propostas para programa de boas práticas higiênicas na manipulação de alimentos [Dissertação]. Curitiba: Universidade Federal do Paraná; 2005.

16. Sample Size Calculate. [acesso em: 02 fev. 2012]. Disponível em: https://www.surveysystem.com/ sscalc.htm

17. American Public Health Association. Compedium of methods for the microbiological examination of foods. 4 ed. Washington DC.: APHA; 2001.

18. International Commission on Microbiological Specifications for Foods. Microorganisms in food-2. Sampling for microbiological analysis: principles and specific applications is the only comprehensive publication on statistically based sapling plans for foods. Toronto: University of Toronto Press; 1986. 
19. Brasil. Ministério da Saúde. Secretaria da Vigilância Sanitária. Resolução RDC no 12,2 de janeiro de 2001. Regulamento técnico sobre os padrões microbiológicos para alimentos. Diário Oficial da União 10 jan. 2001; Seção 1:45-53.

20. Brasil. Ministério da Agricultura Pecuária e Abastecimento. Instrução normativa n. 62, de 26 de agosto de 2003. Métodos analíticos oficiais para análises microbiológicas para controle de produtos de origem animal e água. Diário Oficial da União 18 set. 2003.

21. São Paulo. Secretaria do Estado de Saúde. Aprova o Regulamento Técnico sobre boas práticas para estabelecimentos comerciais de alimentos e para serviços de alimentação, e o roteiro de inspeção, anexo. Portaria CVS 5, de 09 de abril de 2013. Diário Oficial do Estado 19 apr. 2013; Seção I.

22. Valente D, Passos ADC. Avaliação crítica da ficha de inspeção em estabelecimentos da área de alimentos. Hig Alim. 2003; 17(111):37-48.

23. Mello JF, Schneider S, Lima MS, Frazzon J, Costa M. Avaliação das condições de higiene e da adequação às boas práticas em unidades de alimentação e nutrição no município de Porto Alegre RS. Alim Nutr. 2013; 24(2):175-182.

24. São José JFB, Coelho AIM, Ferreira KR. Avaliação das boas práticas em unidade de alimentação e nutrição no município de Contagem - MG. Alim Nutr. 2011; 22(3):479-487.

25. Visser S, Giatti LL, Carvalho RAC, Guerreiro JCH. Study of the association between socioenvironmental factors and the prevalence of intestinal parasitosis in the suburbs of the city of Manaus in the state of Amazonas, Brazil. Cienc Saude Col. 2011; 16(8):3481-3492.

26. Siqueira LP, Shinohara NKS, Lima RMT, Paiva JE, Lima Filho JL, Carvalho IT. Microbiological evaluation of drinking water used in feeding units. Cienc Saude Col. 2010; 15(1):63-66.

27. Santos MHR, Santos Junior G, Bortolozo EAF. Avaliação higiênico-sanitária da manipulação de alimentos, a nível residencial, a partir da ocupação do responsável pelo processamento. Rev Bras Tecn Agroind. 2011; 5(1):346-355.

28. Rodrigues KL, Gomes JP, Conceição RCS, Brod CS, Carvalhal JB, Aleixo JAG. Condições higiênicosanitárias no comércio ambulante de alimentos em Pelotas-RS. Cienc Tecnol Alim. 2003; 23(3):447-452.

29. Lundgren PU, Silva JS, Maciel JF, Fernandes TM. Perfil da qualidade higiênico-sanitária da carne bovina comercializada em feiras livres e mercados públicos de João Pessoa/PB-Brasil. Alim Nutr.2009; 20(1):113-119.

30. Coelho AIM, Milagres RCRM, Martins JFL, Azeredo RMC, Santana AMC. Contaminação microbiológica de ambientes e de superfícies em restaurantes comerciais. Cienc Saúde Col. 2010; 15(Suppl. 1):1597-1606.

31. Brasil. Agência Nacional de Vigilância Sanitária. Resolução nº. 216, de 15 de setembro de 2004. Dispõe sobre Regulamento Técnico de Boas Práticas para Serviços de Alimentação. Diário Oficial da União 16 set. 2004.

32. Alves GM, Ueno M. Restaurantes self-service: segurança e qualidade sanitária dos alimentos servidos. Rev Nutr. 2010; 23(4):573-580. 
33. Feng P, Weagant SD, Grant MA. Enumeration of Escherichia coli and the Coliform Bacteria. In: Bacteriologycal analytical manual online. 2002. [acesso em: 25 out. 2013]. Disponível em: http:// www.fda.gov/Food/FoodScienceResearch/LaboratoryMethods/ucm064948.htm

34. Oliveira ACG, Seixas ASS, Sousa CP, Souza CWO. Microbiological evaluation of sugarcane juice sold at street stands and juice handling conditions in São Carlos, São Paulo, Brazil. Cad Saúde Pública 2006; 22(5):1111-1114.

35. Bezerra ACD, Reis RB, Bastos DHM. Microbiological quality of hamburgers sold in the streets of Cuiabá - MT, Brazil and vendor hygiene-awareness. Cienc Tecnol Aliment. 2010; 30(2):520-524.

36. Silva MP, Cavalli DR, Oliveira TCRM. Avaliação do padrão coliformes a $45^{\circ} \mathrm{c}$ e comparação da eficiência das técnicas dos tubos múltiplos e Petrifilm EC na detecção de coliformes totais e Escherichia coli em alimentos. Cienc Tecnol Aliment. 2006; 26(2):352-359.

37. Mercado M, Ávila J, Rey M, Montoya M, Gamboa A, Carrascal AK, et al. Brotes por Salmonella spp., Staphylococcus aureus y Listeria monocytogenes asociados al consumo de pollo. Biomédica (Bogotá) 2012; 32:375-385.

38. Forsythe SJ. Microbiologia da segurança alimentar. Porto Alegre: Artmed; 2002.

39. Bayona MAR. Evaluación microbiológica de alimentos adquiridos en la vía pública en un sector del norte de Bogotá. Rev U.D.C.A Actual Divulg Cient. 2009; 12(2):9-17.

40. Connor BA, Schwartz E. Typhoid and paratyphoid fever in travellers. The Lancet Infectious Diseases 2005; 5(10):623-628.

41. Maia ICP, Monteiro MAM, Fonseca JL, Coelho MRL, Lopes SLC. Análise da contaminação de utensílios em unidades de alimentação e nutrição hospitalar no município de Belo Horizonte-MG. Alim Nutr. 2011; 22(2):265-271.

42. Andrade NJ, Silva RMM, Brabes KCS. Avaliação das condições microbiológicas em unidades de alimentação e nutrição. Cienc Agrotec. 2003; 26(3):590-596.

43. Tartler N, Fortuna JL. Microbiological quality of hands and gloves and evaluation hygienicalsanitary of the food handlers in a feeding's square in Teixeira de Freitas city, Bahia. R Bras Cien Vet. 2012; 19(2):104-108.

44. Grando FW, Scapin D, Malheiros PS, Rossi EM, Tondo EC. Suscetibilidade a antimicrobianos de Staphylococcus aureus isolados de manipuladores de indústria de laticínios. Alim Nutr. 2008; 19(4):467-471.

45. Saccol ALF, Rubim BA, Mesquita MO, Welter L. Importância de treinamento de manipuladores em boas práticas. Disc Scientia 2006; 7(1):91-99.

Recebido: $23 / 02 / 2017$

Revisado: 28/06/2017

Aceito: 25/08/2017 